\title{
Primary Gastric Squamous Cell Carcinoma Presenting as a Huge Subepithelial Tumor: A Case Report
}

\author{
II Hyun Baek ${ }^{1}$, Jae Hyuck Jun ${ }^{1}$, Dong-Wook Kang ${ }^{2}$
}

'Department of Gastroenterology, Eulji University Hospital, Eulji University School of Medicine, Daejeon, Korea

2Department of Pathology, Eulji University Hospital, Eulji University School of Medicine, Daejeon, Korea

\section{ABSTRACT}

Primary gastric squamous cell carcinoma is a very rare cancer whose mechanism has not been clearly elucidated. To date, less than 100 cases have been reported. However, only one case was reported to be presented as a subepithelial tumor. A 69-year-old woman complained of melena, dizziness for one month, and anorexia for two months. Esophagogastroduodenoscopy revealed a large bleeding subepithelial tumor in the upper body of the stomach. Endoscopic biopsy diagnosed with gastric squamous cell carcinoma. In abdominal computed tomography (CT), large, poorly heterogeneous enhancing, intraluminal protruding masses were observed in the upper body of the stomach, and several regional lymph node enlargements were seen around the stomach. There were no other abnormal findings or metastasis in chest CT and bone scan. The patient is being followed up because of refusing any further treatment after endoscopic hemostasis.

Key words: primary squamous cell carcinoma, subepithelial tumour, incisional biopsy, stomach

\section{INTRODUCTION}

Primary gastric squamous cell carcinoma is a very rare cancer that accounts for only $0.04-0.07 \%$ of all gastric cancers (1). The cause of this cancer has not yet been clearly identified. The cancer usually occurs in men, with a male to female ratio of $5: 1$ (2-3). Most cases occur in the sixth decade of life (4). The location of the tumor is the upper (57.1\%), lower (21.4\%) and middle (19.6\%) part of the stomach. The size of the tumor varies from 2.1 to $13 \mathrm{~cm}$ (mean, $6.6 \pm 0.3 \mathrm{~cm}$ ) (2). To date, less than 100 cases have been reported (5). However, only one case was reported to be presented as a subepithelial tumor (6). Subepithelial tumors in the upper third of the stomach are commonly observed during endoscopy and are easily overlooked because they are mostly benign lesions such as leiomyoma. However, primary gastric squamous cell carcinoma is found mainly in the upper third of the stomach and may very rarely manifest itself as a subepithelial tumor. Therefore, even if the subepithelial tumor is located in the

\author{
Corresponding author: \\ II Hyun Baek, M.D., Ph D, \\ Department of Gastroenterology \\ Eulji University Hospital, Eulji \\ University School of Medicine, 1306 \\ Dunsan-dong, Seo-gu, Daejeon \\ Rep. of KOREA 35233 \\ Telephone: +82-42-611-3063 \\ E-mail: drandrea100@daum.net
}

Received: 29.06.2019 Accepted: 10.08.2019

Copyright () Celsius Publishing House www.sgo-iasgo.com 
upper third of the stomach, follow-up examination or decisive tissue diagnosis is necessary.

We report a case of very rare primary gastric squamous cell carcinoma presenting as a giant ulcerative subepithelial tumor in the upper third of the stomach.

\section{CASE PRESENTATION}

A 69-year-old woman presented with dizziness and melena. She had two months of weight loss and anorexia and one month of dizziness. She was suffering from hypertension. In a past medical history, she had been hospitalized with bleeding gastric ulcer 30 years ago. On physical examination, blood pressure was $111 \mathrm{mmHg} / 64 \mathrm{mmHg}$ and pulse rate was 92/min. Laboratory tests revealed leukocytosis $(15,820$ cells $/ \mathrm{mm}^{3}$ ) and severe anemia (h $6.2 \mathrm{~g} / \mathrm{dL}$ and $\mathrm{h}$ 20.1\%). The tumor marker levels were normal for aFP and CEA, but increased for CA 19-9 (52.46 U / mL (normal range, $0.0 \sim 37.0 \mathrm{U} / \mathrm{mL}$ )). In esophagogastroduodenoscopy, a $7 \mathrm{~cm}$ sized ulcerative subepithelial tumor with active bleeding was observed in the anterior wall of the upper body of the stomach (fig. 1). Pathological examination of biopsy specimens revealed moderately differentiated gastric squamous cell carcinoma with a mosaic pattern of cell arrangement and intracellular bridges. Further immunohistochemistry showed tumor cells with strong expression of p63, which is an indicator of squamous cell carcinoma (fig. 2). Abdominal CT revealed a $7 \mathrm{x}$ $4.5 \mathrm{~cm}$ poorly heterogeneous enhancing, luminal protruding mass at the upper gastric body and several enlarged lymph node in left gastric area (fig. 3). Chest CT showed no evidence of distant metastasis (fig. 4). No metastasis was observed in the bone scan (fig. 5). Based on these findings, the patient was diagnosed with stage III (T3N2MO) gastric cancer according to the TNM classification.

After endoscopic hemostasis, the patient is being followed up because of refusing any further treatment such as surgery or chemotherapy due to advanced age and financial difficulty.

\section{DISCUSSION}

$\mathrm{R}$ "orig described primary squamous cell carcinoma of the stomach for the first time in 1895 (7). Although diagnostic criteria have been standardized and theories exist on the origin of gastric squamous cell carcinoma, the exact pathogenesis is still unknown (8). There are several hypotheses for the development of primary

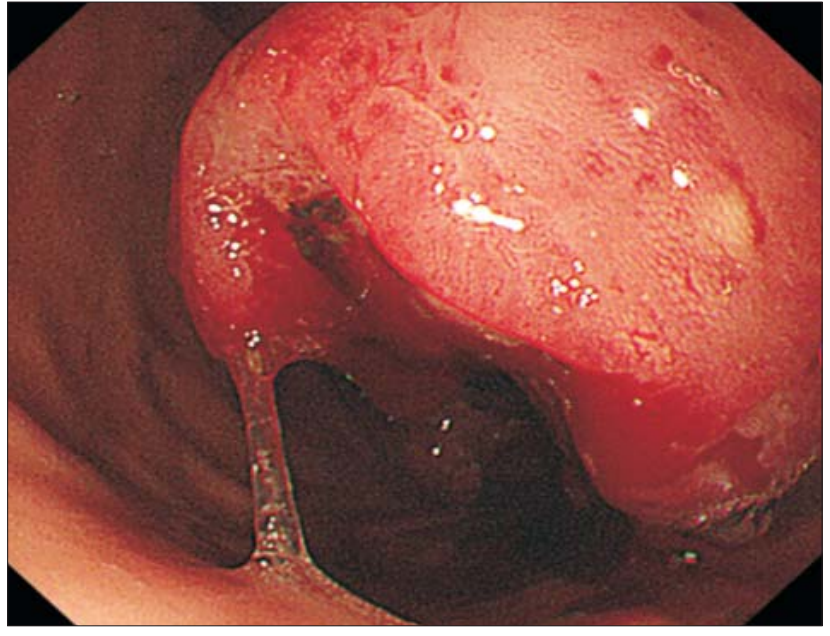

Figure 1 - Esophagogastroduodenoscopy revealed a sevencentimeter sized ulcerated subepithelial mass located in the anterior wall of the upper body of the stomach, without involving the gastroesophageal junction

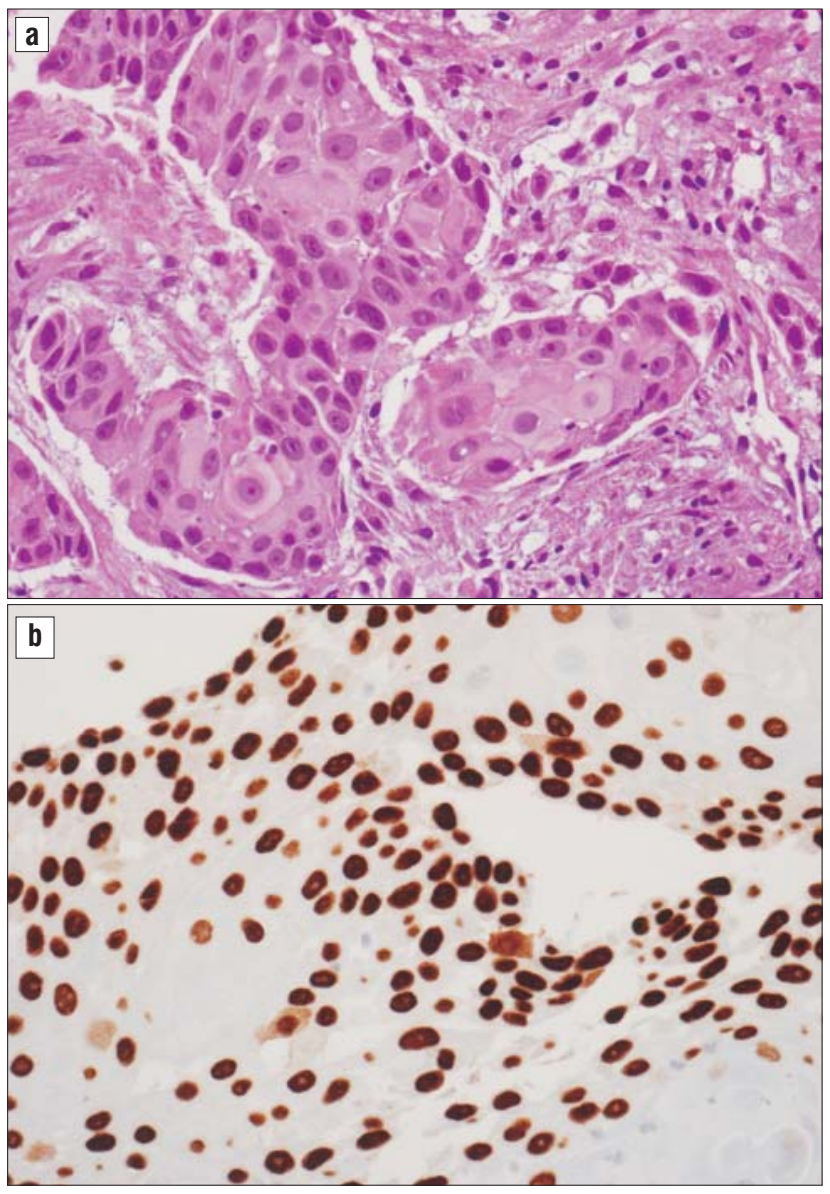

Figure 2 - (a) Pathological examination of the biopsy specimen revealed moderately differentiated gastric squamous cell carcinoma with a mosaic pattern of cell arrangement and intracellular bridges. (H\&E X400); (b) Further immunohistochemistry showed tumor cells with strong expression of $p 63$, which is an indicator of squamous cell carcinoma. (x400) 


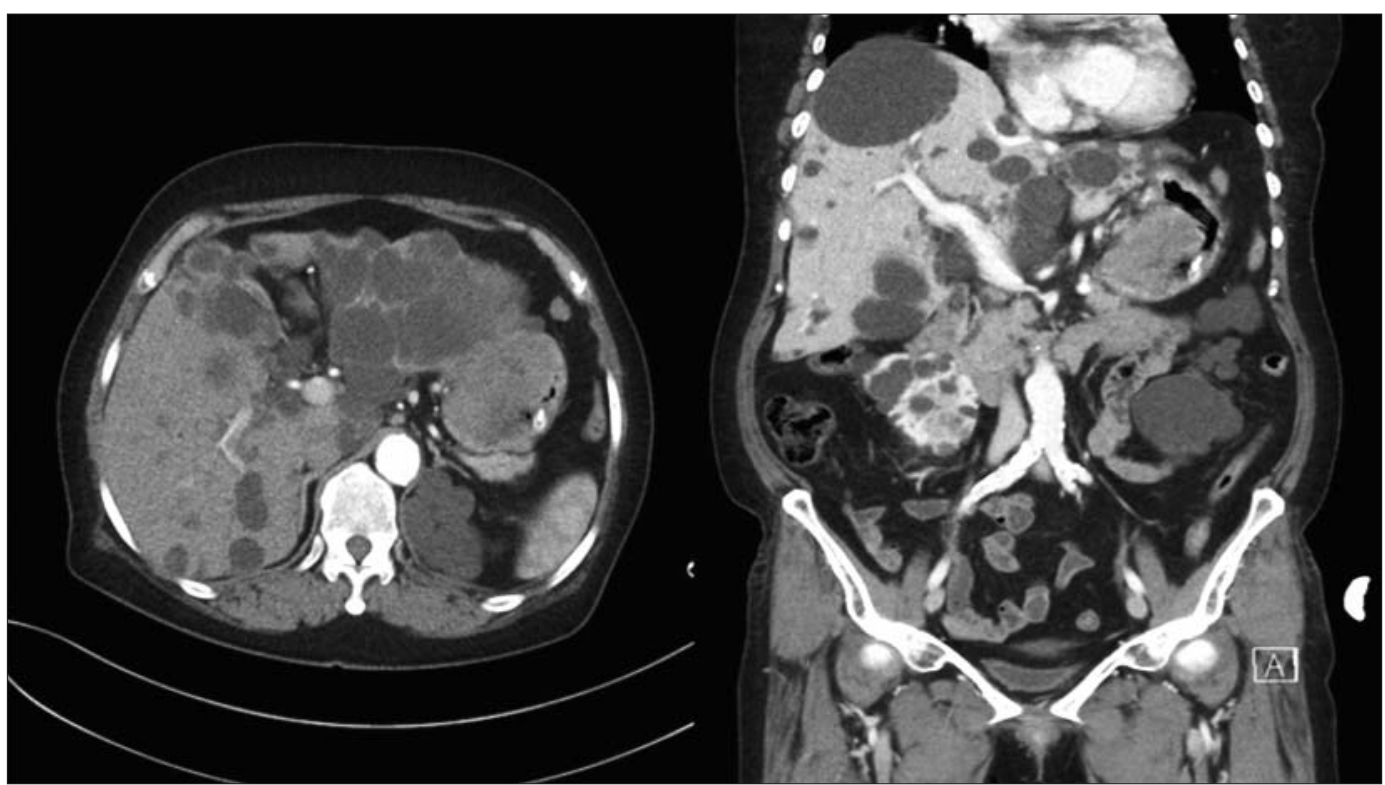

Figure 3 - Abdominal CT revealed a $7 \times 4.5 \mathrm{~cm}$ poorly heterogeneous enhancing, luminal protruding mass at the upper gastric body and several enlarged lymph node in left gastric area but showed no distant metastasis except for the underlying polycystic disease involving the liver \& kidneys

gastric squamous cell carcinoma: (I) (i) Under the exposure of chronic inflammation or tissue damage due to infection, the transformation of pluripotent stem cells in the gastric mucosa causes squamous metaplasia and dysplasia of the epithelium, then squamous cell carcinoma eventually arises (9). (ii) Chronic gastritis which is developed by $\mathrm{H}$. pylori is known to cause repetitive injury and repair of gastric mucosa, resulting in hyperproliferation and increase of mitotic error, then progress to gastric cancer (10). (iii) Stem cells directly become cancer skipping the step of metaplasia or dysplasia. (II) It is possible that squamous cell carcinoma has developed in the heterotopic squamous nodules present in the gastric mucosa (1). In the present case, gastric squamous cell carcinoma appeared as subepithelial tumor. Therefore, we prefer the theory that squamous cell carcinoma arises from the foci of the heterotopic squamous epithelium in the gastric submucosa or other layers, and then subepithelial tumor occurs. (III) The squamous cell carcinoma of the stomach occurs from the squamous metaplasia of the preexisting nonneoplastic glandular epithelium by the process of chronic repair and inflammation. The existence of squamous metaplasia was described for ingestion of corrosive agent (11), linitis plastica associated with congenital syphilis (12), peptic ulcers (13), and during long-term chemotherapy treatment of lymphocytic lymphoma (14).The development of induced squamous cell metaplasia was demonstrated by injection of pyrogallic acid into the

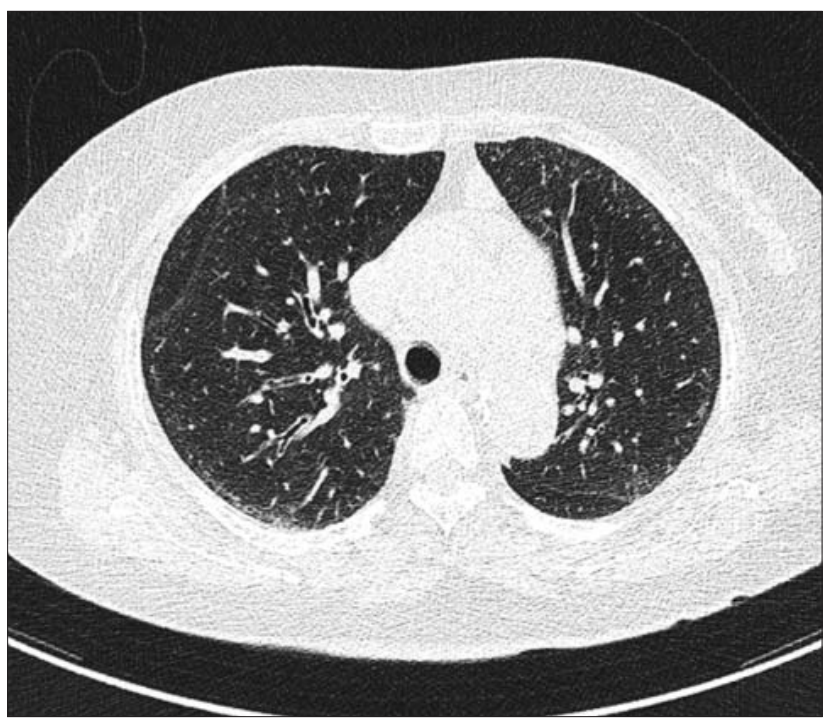

Figure 4 - Chest CT showed no evidence of distant metastasis

submucosal layer in experimental animals. (IV) The preexisting adenocarcinoma may differentiate into squamous metaplasia and eventually turn into squamous cell carcinoma (15). (V) The squamous cell carcinoma of the stomach occurs from endothelium of gastric vessels (16). However, it was considered very unlikely because there was no specific vascular endothelial marker in squamous epithelial cells (5).

To diagnose squamous cell carcinoma, at least one of the four histopathologic criteria must be present (13): (I) cell masses with keratin pearl formation, (II) 


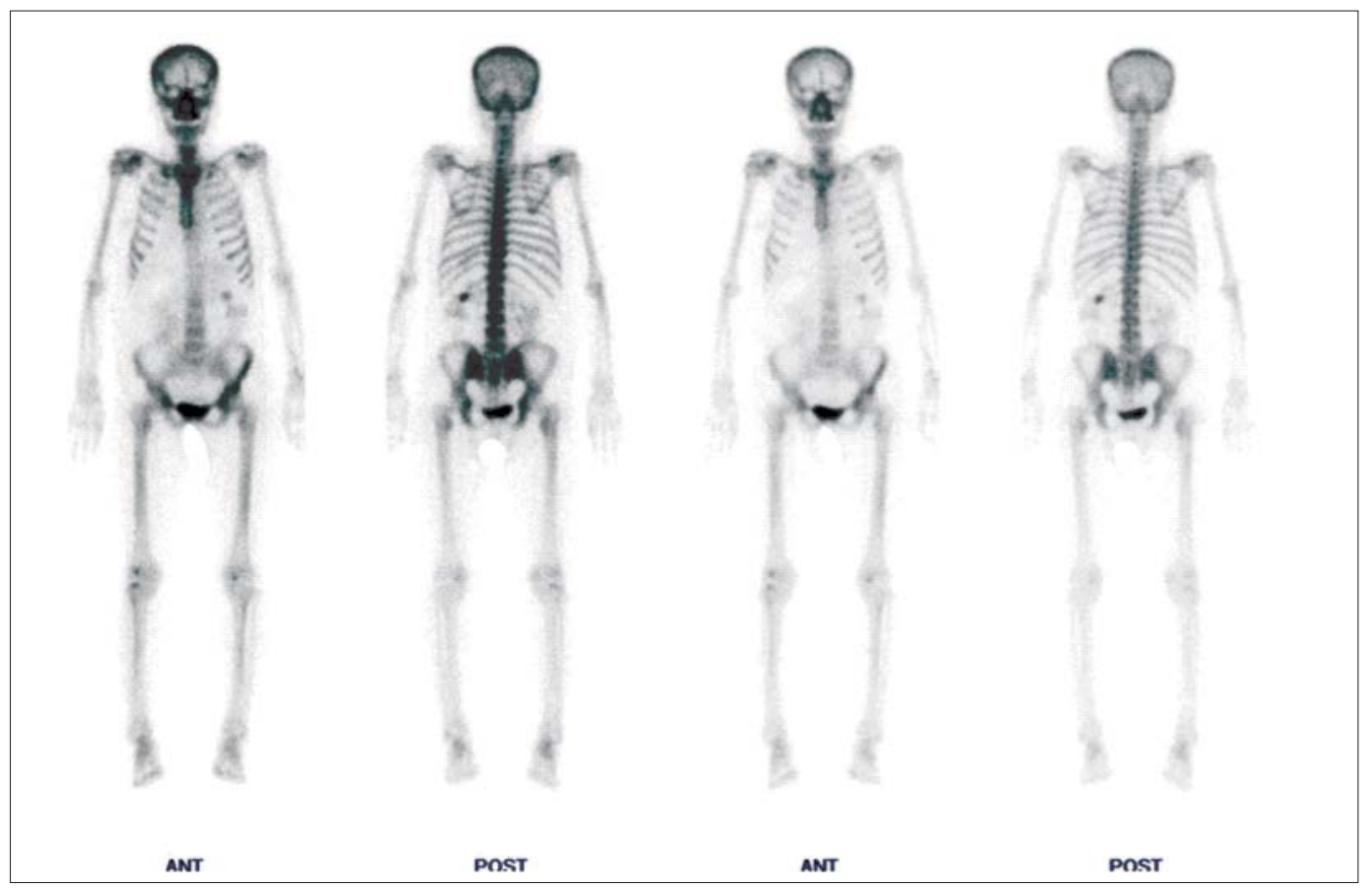

Figure 5 - Bone scan revealed no evidence of bone metastasis

There is a mosaic pattern of cell arrangement with some cells having sharp borders, some cells showing individual cell keratinization, some cells having flattened and elongated nuclei, and strong cytoplasmic eosinophilia with whorl pattern, (III) The intercellular bridges usually occurs in well-differentiated squamous cell carcinoma, and (IV) There is a high concentration of disulfide and/or sulfhydryl groups suggesting the existence of keratin or prekeratin. In this case, we found two, the presence of mosaic pattern and intercellular bridges in the tumor specimen. Therefore, the gastric tumor was diagnosed as squamous cell carcinoma.

Occasionally, histopathology alone is not enough to diagnose squamous cell carcinoma. In such cases, an immunohistochemical approach is useful as an important complementary tool to identify squamous cell carcinoma. In the diagnosis of squamous cell carcinoma, dual expression of p63 and high-molecularweight cytokeratin $5 / 6$ has specificity of $99 \%$ and a sensitivity of $98 \%$ (17). In previous reports, esophageal squamous cell carcinoma consistently showed p63 (100\%) with strong reactivity and CK5/6 (98\% in all cases) (18). In contrast, a combination of CK7 and CK2O is commonly used to detect the origin of adenocarcinoma (including stomach cancer) (19). In this case, tumor cells were positive for p63 immunostaining, thus supporting the pathological diagnosis of squamous cell carcinoma.
If squamous cell carcinoma is found in a region where squamous epithelium is naturally absent, we should determine first whether it is primary or metastatic and, secondly, whether it is genuine squamous cell carcinoma.

The Japanese gastric cancer classification by the Japanese Gastric Cancer Association defines the primary gastric squamous cell carcinoma: (I) All tumor cells are squamous cell carcinoma cells and any area does not contain adenocarcinoma components, (II) There is clear evidence that squamous cell carcinoma is derived directly from the gastric mucosa (20). The widely accepted three diagnostic criteria for primary gastric squamous cell carcinoma are: (I) Tumors should not occur in cardia, (II) The tumor should not extend to the esophagus, and (III) There should be no evidence of squamous cell carcinoma elsewhere in the body (e.g., pancreas, lung, bronchi, uterus, etc.) (8). In our case, the tumor was in the upper body of the stomach and did not extend into the cardia or esophagus. And we did not find any other abnormality or metastatic lesion in the abdominal CT, chest CT and bone scan. We diagnosed this tumor as primary gastric squamous cell carcinoma because our case met the above three criteria.

The prognosis of primary gastric squamous cell carcinoma was reported to be superior (21) or less superior (3) to gastric adenocarcinoma according to the 
stage of diagnosis. However, squamous cell carcinoma of the stomach has generally shown poor results because it is usually diagnosed late to the advanced stage and often aggressively metastasizes to the lymphovascular serosa and liver (2-3). The overall survival rate of the patient is between 7 months and 8 years (22).

Primary gastric suamous cell carcinomas are usually found in the upper third of the stomach, and in particular, they can be presented as subepithelial tumors, as shown in this case. EUS (endoscopic ultrasound), commonly used to diagnose subepithelial tumors, can not accurately predict the malignant potential of gastric subepithelial tumors nor replace histopathological diagnosis (23). In order to assess the correct differential diagnosis and malignancy potential of the gastric subepithelial tumors, not only tissue diagnosis but also immunohistochemistry is essential (24). EUS-FNA(fine needle aspiration) or EUS-guided trucut biopsy, commonly used to get tissue specimens from gastric subepithelial tumors, is difficult to obtain a sufficient amount of tissue for immunohistochemistry. Recently, EUS-based endoscopic incisional target biopsy technique has been attempted to acquire adequate amount of tissue. Its tissue specimens were large enough for definite pathologic diagnosis and immunohistochemical analysis, and its diagnostic yield was very high (89.5\%) (25). Therefore, the endoscopic incisional target biopsy technique enables accurate early diagnosis of malignant subepithelial tumor and can prevent delayed surgery.

\section{CONCLUSION}

Subepithelial tumors in upper part of the stomach are usually benign lesions such as leiomyoma, so they are easily overlooked. However, primary gastric suamous cell carcinomas are usually found in the upper body of the stomach, and in particular, they can be presented as subepithelial tumors, as shown in this case. In conclusion, even if the subepithelial tumor is located in the upper part of the stomach, it is recommened to get decisive tissue diagnosis by endoscopic incisional target biopsy.

\section{Conflict of interst}

All author declare that they have no conflict of interest.

\section{REFERENCES}

1. C. Schmidt, A. Schmid, J. E. L"uttges, B. Kremer, and D. Henne Bruns. Primary squamous cell carcinoma of the stomach. Report of a case and review of literature. Hepato-Gastroenterology. 2001;48:1033-1036.

2. Wakabayashi H, Matsutani T, Fujita I, et al. A rare case of primary squamous cell carcinoma of the stomach and review of the 56 cases reported in Japan. J Gastric Cancer. 2014;14:58-62.

3. Volpe CM, Hameer HR, Masetti P, Pell M, Shaposhnikov YD, Doerr RJ. Squamous cell carcinoma of the stomach. Am Surg. 1995;61:1076-1078.

4. Dursun M, Yaldiz M, Isikdogan A, Yilmaz G, Canoruc F, Ormeci N, Yilmaz S. Primary squamous cell carcinoma of the stomach: a case report and review of the literature. Eur $\mathrm{J}$ Gastroenterol Hepatol 2003:15:329-330.

5. P. Ruck, M. Wehrmann, M. Campbell, H.-P. Horny, G. Breucha, and E. Kaiserling. Squamous cell carcinoma of the gastric stump-a case report and review of the literature. American Journal of Surgical Pathology. 1989;13:317-324.

6. von Waagner W, Wang Z, Picon Al. A rare case of a primary squamous cell carcinoma of the stomach presenting as a submucosal mass. Case Rep Surg. 2015.

7. R. R"orig, Primares Cancroid des Magens, Scheiner, W"urzburg, Germany, 1895.

8. Parks RE. Squamous neoplasms of the stomach. Am J Roentgenol Radium Ther Nucl Med 1967;101:447-449.

9. Balkwill F, Mantovani A. Inflammation and cancer: back to Virchow. Lancet. 2001;357:539-45.

10. Wang TC, Goldenring JR, Dangler C, et al. Mice lacking secretory phospholipase A2 show altered apoptosis and differentiation with Helicobacter felis infection. Gastroenterology. 1998;114:675-89.

11. Eaton H, Tennekoon GE. Squamous cell carcinoma of the stomach following corrosive acid burns. Br J Surg. 1972;59:382-387.

12. Vaughan WP, Straus FH, Paloyan D. Squamous carcinoma of the stomach after luetic linitis plastica. Gastroenterology. 1977;72:945-948.

13. Boswell Jl, Helwig EB. Squamous cell carcinoma and adenoacanthoma of the stomach. A clinicopathologic study. Cancer. 1965;18:181-192.

14. Callwery CD, Sanders MM, Pratt S, Turnbull AD. Squamous cell carcinoma of the stomach: a study of four patients with comments on histogenesis. J Surg Oncol. 1985;29:166-172.

15. Dursun M1, Yaldiz M, Işikdoğan A, Yilmaz G, Canoruç F, Ormeci N, Yilmaz S. Primary squamous cell carcinoma of the stomach: a case report and review of the literature. European Journal of Gastroenterology \& Hepatology. 2003;15:329-330.

16. A. G. Huvos and R. C. Marcove. Adamantinoma of long bones. A clinicopathological study of fourteen cases with vascular origin suggested. The Journal of Bone and Joint Surgery-American Volume. 1975:57:148-154.

17. M. A. DiMaio, S. Kwok, K. D. Montgomery, A. W. Lowe, and R. K. Pai. Immunohistochemical panel for distinguishing esophageal adenocarcinoma from squamous cell carcinoma: a combination of p63, cytokeratin 5/6, MUC5AC, and AGR2 allows optimal subtyping. Human Pathology. 2012;43:1799-1807.

18. DiMaio MA, Kwok S, Montgomery KD, Lowe AW, Pai RK. Immunohistochemical panel for distinguishing esophageal adenocarcinoma from squamous cell carcinoma: a combination of p63, cytokeratin 5/6, MUC5AC, and anterior gradient homolog 2. Hum Pathol. 2012;43:1799-807.

19. Moll R. Molecular diversity of cytokeratins: significance for cell and tumor differentiation. Acta Histochem Suppl. 1991;41:117-27.

20. Japanese Gastric Cancer Association. Japanese classification of gastric carcinoma: 3rd English edition. Gastric Cancer. 2011; 14:101-12.21. Altshuler JH, Shaka JA. Squamous cell carcinoma of the stomach. Review of the literature and report of a case. Cancer 
II Hyun Baek et al

1966;19:831-838.

22. Bonnheim DC, Sarac OK, Fett W. Primary squamous cell carcinoma of the stomach. Am J Gastroenterol 1985;80:91-94.

23. Hwang JH, Rulyak SD, KimmeyMB. American Gastroenterological Association Institute Technical Review on the Management of Gastric Subepithelial Masses. Gastroenterology 2006;130: 2217-2228.
24. Philipper M, Hollerbach S, Gabbert HE, et al. Prospective comparison of endoscopic ultrasound-guided fine needle aspiration and surgical histology in upper gastrointestinal submucosal tumors. Endoscopy 2010;42:300-305.

25. Baek IH, Joo KR, Min KW. How can we avoid unnecessary surgical resection for gastric subepithelial tumours? A multicenter retrospective study in Korea. Surg. Gastroenterol. Oncol. 2018;23:26-32. 